\title{
CORRECTION
}

\section{Correction: Clinical, neuropathological, and genetic characterization of $S T U B 1$ variants in cerebellar ataxias: a frequent cause of predominant cognitive impairment}

Thomas Roux, MD, Mathieu Barbier, PhD, Mélanie Papin, MS, Claire-Sophie Davoine, BS, Sabrina Sayah, PhD, Giulia Coarelli, MD, Perrine Charles, MD, PhD, Cecilia Marelli, MD, PhD, Livia Parodi, PhD, Christine Tranchant, MD, Cyril Goizet, MD, PhD, Stephan Klebe, MD, Ebba Lohmann, MD, Lionel Van Maldergem, MD, PhD, Christine van Broeckhoven, PhD, Marie Coutelier, PhD, Christelle Tesson, PhD, Giovanni Stevanin, PhD, Charles Duyckaerts, MD, PhD, Alexis Brice, MD, Alexandra Durr, MD, PhD (D) and SPATAX network

Genetics in Medicine (2021) 23:2021; https://doi.org/10.1038/s41436-020-01064-y

Correction to: Genetics in Medicine 22, 1851-1862 (2020); https:// doi.org/10.1038/s41436-020-0899-x; published online 27 July 2020

The original version of this Article contained an error in the author name for Lionel Van Maldergem. The family name was incorrectly spelled Van Maldergen. This has now been corrected in both the PDF and HTML versions of the Article. 